\title{
Enzymatic Synthesis of $M_{1}$ G-Deoxyribose
}

$\mathrm{M}_{1} \mathrm{G}$-deoxyribose $\left(\mathrm{M}_{1} \mathrm{G}-\mathrm{dR}, 1, N^{2}\right.$-pyrimido[1,2- $\left.\alpha\right]$ purin-10(3H)-one, or pyrimidopurinone; see structure in Fig. 1.2.2, below) is an endogenous exocyclic DNA adduct formed by the reaction of the dicarbonyl compound malondialdehyde (MDA) with a deoxyguanosine residue in DNA. $\mathrm{M}_{1} \mathrm{G}-\mathrm{dR}$ is an intermediate in the synthesis of a class of modified oligodeoxyribonucleotides that are used to study the mutagenicity and repair of $\mathrm{M}_{1} \mathrm{G}$.

This unit presents two methods for synthesizing $\mathrm{M}_{1} \mathrm{G}-\mathrm{dR}$ using enzymatic coupling. The Basic Protocol describes a procedure for coupling the nucleobase to deoxyribose, in a reaction mediated by the enzyme nucleoside 2 -deoxyribosyltransferase, followed by preparation of the modified base (see Fig. 1.2.1A). Preparation of the enzyme is described in the Support Protocol. The Alternate Protocol uses two commercially available enzymes, purine nucleoside phosphorylase and thymidine phosphorylase (see Fig. 1.2.1B). Although the enzyme preparation step is avoided, additional purification steps are required that increase the time needed to complete the synthesis and decrease the yield (see Commentary).

NOTE: Use deionized, distilled water in all recipes and protocol steps.

\section{ENZYMATIC COUPLING USING NUCLEOSIDE 2'-DEOXYRIBOSYLTRANSFERASE}

Nucleoside 2'-deoxyribosyltransferase (trans- $N$-deoxyribosylase or nucleoside:purine(pyrimidine) deoxyribosyltransferase; E.C. 2.4.2.6) catalyzes the transfer of the deoxyribosyl moiety from a deoxyribonucleoside to any other nucleoside base (see Fig. 1.2.1A). This enzyme is found exclusively in Lactobacilli and related microorganisms that require deoxynucleosides for growth (Carson and Wasson, 1988). The enzyme's broad specificity makes it a useful tool for synthesizing modified deoxyribonucleotides.

This protocol describes the use of this enzyme (see Support Protocol for preparation) to transfer a deoxyriboside from $2^{\prime}$-deoxycytidine to $M_{1} G$ and produce $M_{1} G-d R$. The two synthesis steps can be carried out in a single flask, which decreases the time needed to purify $\mathrm{M}_{1} \mathrm{G}-\mathrm{dR}$ and significantly increases the yield of the reaction.

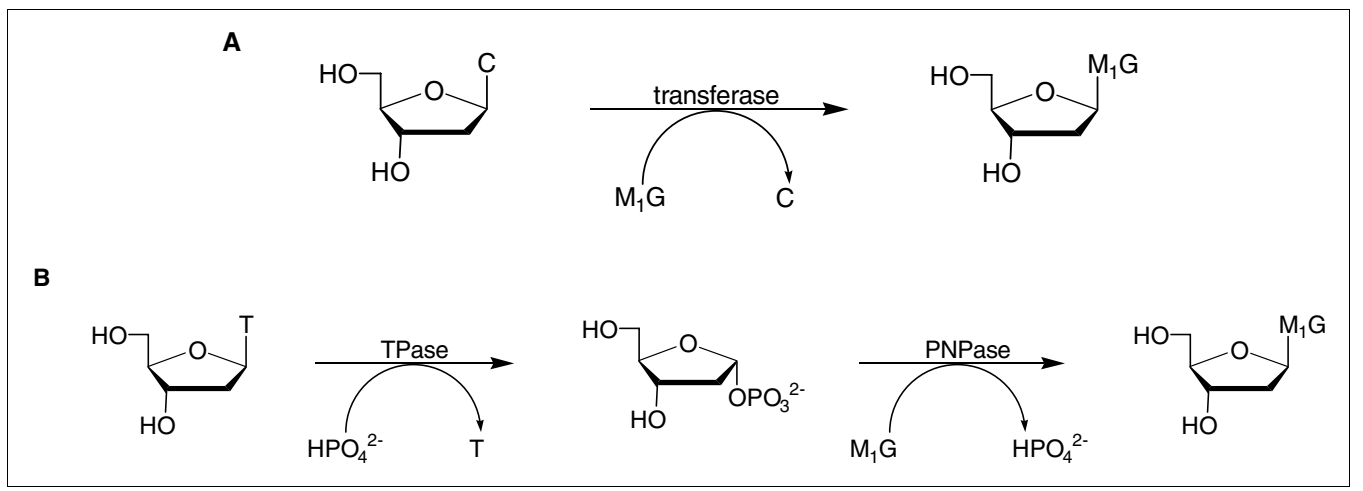

Figure 1.2.1 Enzymatic coupling reactions. (A) Reaction catalyzed by nucleoside 2'-deoxyribosyltransferase (Basic Protocol). (B) Reaction catalysed by thymidine phosphorylase and purine nucleoside phosphorylase (Alternate Protocol).

Contributed by Nathalie C. Schnetz-Boutaud, Marie-Christine Chapeau, and Lawrence J. Marnett Current Protocols in Nucleic Acid Chemistry (2000) 1.2.1-1.2.8

Copyright $\odot 2000$ by John Wiley \& Sons, Inc. 


\section{Materials}

Guanine hydrochloride (Sigma)

$1 \mathrm{~N} \mathrm{HCl}$

Tetraethoxypropane (Aldrich)

Methanol (MeOH; Aldrich)

Potassium carbonate (Aldrich)

Nanopure water (water purified using Nanopure system from

Barnstead/Thermolyne)

MES (2-[N-morpholino]ethanesulfonic acid; Sigma)

2'-Deoxycytidine (dC; Sigma)

$1 \mathrm{~N} \mathrm{NaOH}$

Nucleoside 2'-deoxyribosyltransferase (transferase; see Support Protocol)

Dichloromethane $\left(\mathrm{CH}_{2} \mathrm{Cl}_{2} ;\right.$ Fisher $)$

250-mL round-bottom flask

Oil bath, $70^{\circ} \mathrm{C}$

Magnetic stir plate and stir bar

Ice bath

$\mathrm{pH}$ indicator strips

Büchner funnel

Whatman No. 1 filter paper

Shaking incubator, $37^{\circ} \mathrm{C}$

Silica-gel thin-layer chromatography (TLC) plates

Lyophilizer

Silica gel (60 to 100 mesh; Fisher)

$8 \times 50$-cm chromatography column

\section{Prepare modified base}

1. In a 250 -mL round-bottom flask, dissolve $1 \mathrm{~g}(5.3 \mathrm{mmol})$ guanine hydrochloride in $100 \mathrm{~mL}$ of $1 \mathrm{~N} \mathrm{HCl}$ that has been heated to $70^{\circ} \mathrm{C}$ using an oil bath. Stir on a magnetic stir plate until dissolved.

The dissolution can take from $30 \mathrm{~min}$ to $1 \mathrm{hr}$.

2. Mix $1.3 \mathrm{~mL}(5.86 \mathrm{mmol})$ tetraethoxypropane with $1.25 \mathrm{~mL}$ methanol. Add this dropwise to the solution from step 1 .

Slow addition of tetraethoxypropane favors the formation of the modified base and avoids the polymerization of MDA.

3. Let the reaction mixture stir for $30 \mathrm{~min}$ on a magnetic stir plate, then cool to $0^{\circ} \mathrm{C}$ in an ice bath.

Cooling moderates the neutralization reaction to follow.

4. Neutralize by slowly adding potassium carbonate to $\mathrm{pH} 6$, verifying the $\mathrm{pH}$ using $\mathrm{pH}$ indicator strips. Take special care when approaching the desired $\mathrm{pH}$.

5. Remove unreacted guanine by filtering through Whatman no. 1 filter paper on a Büchner funnel under vacuum. Wash the precipitate twice with $20 \mathrm{~mL}$ of Nanopure water.

The filtrate contains the modified base. The yield of the reaction is estimated at $30 \%$.

Enzymatic Synthesis of $M_{1}$ G-Deoxyribose
6. Add MES to a final concentration of $0.5 \mathrm{M}$.

MES is used to buffer the enzymatic reaction. 
7. Add $1.2 \mathrm{~g}(5.3 \mathrm{mmol}) 2^{\prime}$-deoxycytidine.

8. Equilibrate the solution to $\mathrm{pH} 6.0$ with $1 \mathrm{~N} \mathrm{HCl}$ or $1 \mathrm{~N} \mathrm{NaOH}$.

\section{Perform enzymatic coupling}

9. Add an appropriate amount of nucleoside $2^{\prime}$-deoxyribosyltransferase solution and incubate overnight at $37^{\circ} \mathrm{C}$ with shaking.

Each enzymatic preparation has its own concentration and activity, which must be tested empirically by assaying the preparation's ability to convert a small quantity of $M_{1} G$ to $M_{1} G d R$ to estimate the amount to use for the full-scale reaction.

10. Check the progress of the reaction by TLC on silica-gel plates using 9:1 (v/v) $\mathrm{CH}_{2} \mathrm{Cl}_{2} / \mathrm{MeOH}$ as the mobile phase.

Add $50 \mu \mathrm{L}$ methanol to $50 \mu \mathrm{L}$ of reaction mix and spot on TLC plate using a capillary tube. If the reaction is not complete, add more enzyme and $d C$, but not more than one-fifth the amount used at the start of the reaction, and incubate an additional 6 to 12 hours.

11. Once the reaction is complete, lyophilize the reaction mixture to dryness.

12. Purify the crude product on a silica-gel column using 9:1 (v/v) $\mathrm{CH}_{2} \mathrm{Cl}_{2} / \mathrm{MeOH}$ for equilibration and elution. Elute by gravity and collect $50-\mathrm{mL}$ fractions.

The lyophilized reaction mixture may be added directly to the top of the packed column.

13. Confirm the purity of the product by ${ }^{1} \mathrm{H}$ NMR. Store the product under nitrogen at $-20^{\circ} \mathrm{C}$. Under these conditions, it is stable for several years.

A typical spectrum is presented in Figure 1.2.2. The estimated yield is $10 \%$ to $15 \%$.

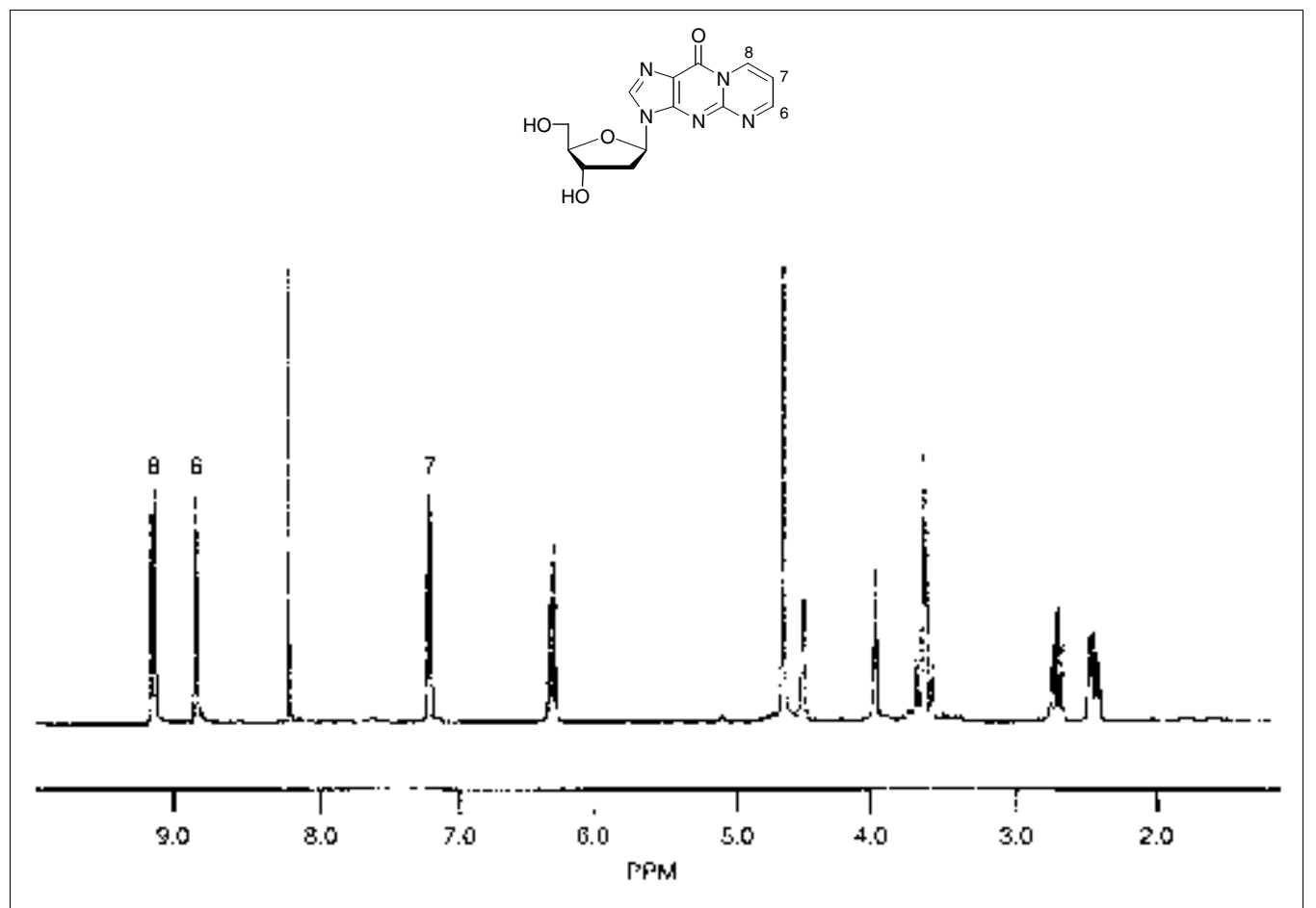

Figure 1.2.2 ${ }^{1} \mathrm{H}$ NMR spectrum of $\mathrm{M}_{1}-\mathrm{GdR}$ in $\mathrm{D}_{2} \mathrm{O}$.

Synthesis of Modified Nucleosides 
PREPARATION OF NUCLEOSIDE 2'-DEOXYRIBOSYLTRANSFERASE

Nucleoside 2'-deoxyribosyltransferase was first isolated by McNutt (1952). Partial purification of the enzyme from Lactobacillus leichmannii has been described by Beck and Levin (1963), and its complete purification and crystallization by Uerkvitz (1971). This protocol is based upon the latter method. The partial purification described here is sufficient for obtaining enzyme to be used in the Basic Protocol.

\section{Materials}

Lactobacillus broth AOAC (see recipe)

Lactobacillus helveticus culture

$0.15 \mathrm{M} \mathrm{NaCl}\left(4^{\circ} \mathrm{C}\right)$

$50 \mathrm{mM}$ potassium phosphate buffers, $\mathrm{pH} 6.0$ and 6.9 (see APPENDIX $2 A$; dilute with

Nanopure water to desired molarity)

$50 \mathrm{mM}$ potassium phosphate, $\mathrm{pH} 5.1$, containing $10 \mathrm{~g} / \mathrm{L} \mathrm{NaCl}$

250-mL Erlenmeyer flask

Centrifuge and rotors (e.g., Sorvall GS-3 and SS-34)

Microtip sonicator (Virsonic 100)

BCA Protein Assay (Pierce; optional) or equivalent

\section{Purify the enzyme}

1. Using aseptic technique, place $25 \mathrm{~mL}$ of Lactobacillus broth in an Erlenmeyer flask. Add a loopful of Lactobacillus helveticus commercial stock and incubate overnight at $37^{\circ} \mathrm{C}$ without shaking.

2. Transfer the $25-\mathrm{mL}$ culture into $1000 \mathrm{~mL}$ of fresh Lactobacillus broth. Grow $18 \mathrm{hr}$ at $37^{\circ} \mathrm{C}$ without shaking.

3. Cool to $4^{\circ} \mathrm{C}$ and divide into centrifuge tubes. Centrifuge the tubes $10 \mathrm{~min}$ at $7000 \times$ $g\left(6500 \mathrm{rpm}\right.$ in a GS-3 rotor), $4^{\circ} \mathrm{C}$.

4. Resuspend pellets in $100 \mathrm{~mL}$ cold $0.15 \mathrm{M} \mathrm{NaCl}$ and centrifuge again as in step 3 . Repeat.

5. Suspend cell pellets in a total of $20 \mathrm{~mL}$ of $50 \mathrm{mM}$ potassium phosphate, $\mathrm{pH} 6.0$.

6. Sonicate 10 times for 1 min each time with a Virsonic 100 microtip sonicator at a setting of 4 to 5 .

7. Centrifuge $30 \mathrm{~min}$ at $28,000 \times g(15,000 \mathrm{rpm}$ in an SS-34 rotor $), 4^{\circ} \mathrm{C}$. Save the supernatant.

8. Wash the pellets twice by resuspending in a minimal volume of $0.15 \mathrm{M} \mathrm{NaCl}$ and centrifuging as in step 7. Save the supernatants.

9. Combine the supernatants from the previous two steps, and dialyze overnight against $4 \mathrm{~L}$ of $50 \mathrm{mM}$ potassium phosphate, $\mathrm{pH} 5.1$, containing $10 \mathrm{~g} / \mathrm{L} \mathrm{NaCl}$.

10. Heat $10 \mathrm{~min}$ at $55^{\circ} \mathrm{C}$, then immediately place on ice.

The heating denatures all heat-sensitive proteins that are present in the extract, thereby enriching for transferase, which is not heat sensitive.

11. Centrifuge again as in step 7.

Enzymatic

Synthesis of $\mathbf{M}_{1}$ G-Deoxyribose
12. Collect the supernatant and dialyze overnight in $50 \mathrm{mM}$ potassium phosphate, $\mathrm{pH}$ 6.9 . 
To quantify the amount of total protein purified, the BCA Protein Assay (Pierce) can be used.

For the purpose of this experiment, this level of purification is sufficient. Store the protein in aliquots at $-20^{\circ} \mathrm{C}$ or proceed to coupling experiments (see Basic Protocol).

\section{Assay the enzyme}

13. Prepare five 5-mL aliquots of filtrate containing $\mathrm{M}_{1} \mathrm{G}$ (see Basic Protocol, step 8).

14. Add to the filtrate $50,100,150,200$, and $250 \mu \mathrm{L}$ of supernatant containing the enzyme (from step 12).

15. Incubate overnight at $37^{\circ} \mathrm{C}$ with shaking.

16. Spot $10 \mu \mathrm{L}$ of each reaction mixture three times on a TLC plate using 9:1 (v/v) $\mathrm{CH}_{2} \mathrm{Cl}_{2} / \mathrm{MeOH}$ as the mobile phase. Determine presence of $\mathrm{M}_{1} \mathrm{G}-\mathrm{dR}$.

\section{ENZYMATIC COUPLING USING PURINE NUCLEOSIDE PHOSPHORYLASE AND THYMIDINE PHOSPHORYLASE}

Purine nucleoside phosphorylase (PNPase; E.C. 2.4.2.1) catalyzes the displacement of phosphate from deoxyribose-1-phosphate on purines and purine analogs. The stereochemistry of purine attachment produces the naturally occurring $\beta$-isomers. Although ribose-1-phosphate is commercially available, it may be more conveniently and cost-effectively generated in situ by thymidine phosphorylase (TPase; E.C. 2.4.2.4)-catalyzed phosphorolysis of thymidine (see Fig. 1.2.1).

This Alternate Protocol can be used to avoid the transferase preparation required for the Basic Protocol. First the modified base is synthesized and purified, then the enzymatic coupling is initiated, and finally the product is separated on a medium-performance liquid chromatography (MPLC) column. Due to the instability of $\mathrm{M}_{1} \mathrm{G}$, only $2 \%$ to $5 \%$ of product is recovered, regardless of the yields achieved in the transribosylation step.

Additional Materials (also see Basic Protocol)

Thymidine (e.g., Sigma)

Purine nucleoside phosphorylase (PNPase; Sigma)

Thymidine phosphorylase (TPase; Sigma)

$20 \mathrm{mM}$ potassium phosphate, $\mathrm{pH} 7.3$ (APPENDIX 2A)

MPLC buffer: $20 \%$ methanol in water

UV lamp (254 and $365 \mathrm{~nm}$ )

mPLC column (Baker $\left.\mathrm{C}_{18}-40 \mu \mathrm{m}, 30 \times 500 \mathrm{~mm}\right)$

\section{Prepare modified base}

1. Prepare modified base (see Basic Protocol, steps 1 to 5).

2. Concentrate the filtrate under vacuum.

3. Prepare a slurry of the residue with $\sim 10 \mathrm{~g}$ silica gel.

4. Purify by chromatography on a silica-gel column using $9: 1(\mathrm{v} / \mathrm{v}) \mathrm{CH}_{2} \mathrm{Cl}_{2} / \mathrm{MeOH}$ for equilibration and elution.

5. Collect and combine the fractions containing $\mathrm{M}_{1} \mathrm{G}$ as determined by UV fluorescence.

$$
M_{I} G \text { base is fluorescent under the long-wavelength (365 } \mathrm{nm} \text { ) of the UV lamp. }
$$

ALTERNATE PROTOCOL

Synthesis of Modified Nucleosides 
6. Evaporate under vacuum and store under nitrogen at $-20^{\circ} \mathrm{C}$.

7. Verify the purity of $\mathrm{M}_{1} \mathrm{G}$ base by ${ }^{1} \mathrm{H}$ NMR.

The estimated yield is $2 \%$ to $5 \%$.

\section{Perform enzymatic coupling}

8. Dissolve $37 \mathrm{mg}(0.2 \mathrm{mmol}) \mathrm{M}_{1} \mathrm{G}$ base and $73 \mathrm{mg}(0.6 \mathrm{mmol})$ thymidine in $200 \mathrm{~mL}$ of $20 \mathrm{mM}$ potassium phosphate buffer. Adjust the $\mathrm{pH}$ to 7.3 with $1 \mathrm{~N} \mathrm{HCl}$ or $1 \mathrm{~N}$ $\mathrm{NaOH}$.

9. Add $20 \mathrm{U}$ TPase and $30 \mathrm{U}$ PNPase.

10. Incubate the solution $18 \mathrm{hr}$ at $37^{\circ}$ to $39^{\circ} \mathrm{C}$ with shaking.

Verify the completion of the enzymatic coupling by thin-layer chromatography (see Basic Protocol, step 10). If the reaction is not complete, continue the purification without further incubation.

11. Concentrate the reaction under vacuum.

This and all subsequent vacuum steps may be performed using a side-arm flask with water aspiration.

12. Prepare a slurry of the residue with $\sim 5 \mathrm{~g}$ silica gel.

13. Purify by chromatography on a silica-gel column using $9: 1(\mathrm{v} / \mathrm{v}) \mathrm{CH}_{2} \mathrm{Cl}_{2} / \mathrm{MeOH}$ for equilibration and elution. Elute by gravity and collect $50-\mathrm{mL}$ fractions.

14. Collect the fractions containing $\mathrm{M}_{1} \mathrm{G}-\mathrm{dR}$ as determined by yellow fluorescence at $365 \mathrm{~nm}$.

$M_{1} G$ and $M_{l} G-d R$ have different elution times.

15. Evaporate to dryness under vacuum. Redissolve two aliquots in $2 \mathrm{~mL} \mathrm{MPLC}$ buffer each.

16. Purify by MPLC on a Baker $\mathrm{C}_{18} 40 \mu \mathrm{m}, 30 \times 500-\mathrm{mm}$ column, eluting with $20 \%$ methanol in water (isocratic) at a flow rate of $3 \mathrm{~mL} / \mathrm{min}$.

This second column is necessary to separate thymidine from $M_{1} G-d R$.

17. Collect the fluorescent fractions and evaporate to dryness under vacuum.

18. Verify the purity of the product by ${ }^{1} \mathrm{H} \mathrm{NMR}$.

A typical spectrum is presented in Figure 1.2.2 (see Basic Protocol). The estimated yield is $50 \%$ to $60 \%$.

\section{REAGENTS AND SOLUTIONS}

Use Nanopure water (water purified using Nanopure system from Barnstead/Thermolyne) where indicated, and deionized, distilled water in all other recipes and protocol steps. For common stock solutions, see APPENDIX 2A; for suppliers, see SUPPLIERS APPENDIX.

\section{Lactobacillus broth AOAC}

Enzymatic Synthesis of $\mathbf{M}_{1}$ G-Deoxyribose

Mix $38 \mathrm{~g}$ of Lactobacillus broth AOAC (Difco) into $1000 \mathrm{~mL}$ Nanopure water. Heat to boiling for $2 \mathrm{~min}$. Autoclave $30 \mathrm{~min}$ and allow to cool to room temperature. Prepare fresh for each run. 


\section{COMMENTARY}

\section{Background Information}

Adducts formed between electrophiles and nucleic acid bases are believed to play a key role in chemically induced mutations and cancer (Singer and Grunnenberger, 1983). Chemical synthesis of deoxynucleoside adducts provides not only authentic standards for comparison to biologically derived materials but also reagents for the synthesis of adducted nucleotides (Basu and Essigmann, 1988). The preparation of certain classes of deoxynucleoside adducts is problematic because of the instability of the intermediates under the conditions used for synthetic manipulations (e.g., the acid lability of purine deoxyribosides). Synthetic approaches to preparing sensitive deoxynucleosides include coupling of adducted bases to activated deoxyribose derivatives (Srivasta et al., 1988) and attachment of deoxyribose moieties to modified bases (Garner and Ramakanth, 1988). However, there are inherent difficulties in controlling both the regiochemistry (e.g., to achieve attack at the N7 versus N9 atom of a purine) and the stereoselectivity (e.g., an $\mathrm{S}_{\mathrm{N}} 2$ attack on a sugar isomer is needed to generate the desired linkage). Chemical synthesis increases the difficulty of obtaining the correct regioselectivity, whereas enzymatic coupling on nonmodified bases generates only one regioselective isomer.

Enzymatic coupling of purine or pyrimidine analogs to deoxyribose has been used to synthesize a number of compounds, including isotopically substituted deoxynucleosides, antitumor agents, and biological active molecules (Holy and Votruba, 1987; Krenitsky et al., 1981, 1986; Muller et al., 1996). When PNPase and TPase are used on $\mathrm{M}_{1} \mathrm{G}$ (see Alternate Protocol), N9 linkage is shown to be preferred over N7. With the use of transferase (see Basic Protocol), complete regioselectivity (for the N9 isomer only) is obtained.

\section{Critical Parameters}

Since the pyrimidopurinone $\mathrm{M}_{1} \mathrm{G}-\mathrm{dR}$ synthesized in these procedures is base labile, the $\mathrm{pH}$ must stay below 7.5 for all protocols. $\mathrm{M}_{1} \mathrm{G}$ base is even less stable than $\mathrm{M}_{1} \mathrm{G}-\mathrm{dR}$.

The Basic Protocol does not require purification of the modified base; the transferase can be added to the crude mixture. The desired nucleoside can be purified by simple column chromatography. This strategy not only shortens the time required for the synthesis, but also significantly improves the yield. In comparison the Alternate Protocol, which uses a combination of two commercially available enzymes, is more demanding in terms of time and purification. $\mathrm{M}_{1} \mathrm{G}$ base must be purified; moreover, when the crude mixture is reacted with the combination of PNPase and TPase, transribosylation is inefficient. Also, due to the close polarity of thymidine and $\mathrm{M}_{1} \mathrm{G}-\mathrm{dR}$ (in a variety of solvents system used), a combination reversed-phase and straight-phase column must be employed to obtain pure material.

The transferase used in the Basic Protocol and prepared in the Support Protocol has a higher selectivity and produces only the N9 isomer. The two-enzyme method of the Alternate Protocol produces a mixture of N7 and N9, increasing the difficulty of purification. Once a stock solution of transferase is prepared, the Basic Protocol is much easier to perform, less time-consuming, and gives better yields.

\section{Anticipated Results}

The two protocols described in this unit allow preparation of the desired modified nucleoside in good yields. The Basic Protocol should give yields between $10 \%$ and $15 \%$ and the Alternate Protocol gives between 2\% and $5 \%$. Figure 1.2.2 shows the ${ }^{1} \mathrm{H}$ NMR spectrum of $\mathrm{M}_{1} \mathrm{G}-\mathrm{dR}$.

\section{Time Considerations}

Preparation of transferase (see Support Protocol) may take 3 to 4 days. The one-step condensation procedure using transferase (see Basic Protocol), from the synthesis of the modified base to the purification of the nucleoside, should take $24 \mathrm{hr}$ with lyophylization. The alternative method using commercial phosphorylases (see Alternate Protocol) should take 2 or 3 days.

\section{Literature Cited}

Basu, A.K. and Essigmann, J.M. 1988. Site-specifically modified oligonucleotides as probes for the structural and biological effects of DNA-damaging agents. Chem. Res. Toxicol. 1:1-18.

Beck, W.S. and Levin, M. 1963. Purification, kinetics, and repression control of bacterial trans- $N$ deoxyribosylase. J. Biol. Chem. 238:702.

Carson, D.A. and Wasson, D.B. 1988. Synthesis of 2',3'-dideoxynucleosides by enzymatic transglycosylation. Biochem. Biophys. Res. Comm. 155:829-834.

Garner, P. and Ramakanth, S. 1988. A regiocontrolled synthesis of N7- and N9-guanine nucleosides. J. Org. Chem. 53:1294-1298.
Synthesis of Modified Nucleosides 
Holy, A. and Votruba, I. 1987. Facile preparation of purine and pyrimidine 2-deoxy- $\beta$-D-ribonucleosides by biotransformation on encapsulated cells. Seventh symposium on the Chemistry of Nucleic Acid Components August 30-September 5, 1987. Nucleic Acids Symp. Ser. 18:69-72.

Krenitsky, T.A., Kozallka, G.W., and Tuttle, J.V. 1981. Purine nucleoside synthesis, an efficient method employing nucleoside phosphorylases. Biochemistry 20:3615-3621.

Krenitsky, T.A., Rideout, J.L., Chao, E.Y., Koszalka, G.W., Gurney, F., Crouch, R.C., Cohn, N.K., Wolberg, G., and Vinegar, R. 1986. Imidazo[4,5c]pyridines (3-deazapurines) and their nucleosides as immunosuppresive and antiinflammatory agents. J. Med. Chem. 29:138-143.

McNutt, W.S. 1952. The enzymically catalysed transfer of the deoxyribosyl group from one purine or pyrimidine to another. Biochem. J. 50:384.

Muller, M., Hutchinson, L.K., and Guengerich, F.P. 1996. Addition of deoxyribose to guanine and modified DNA bases by Lactobacillus helveticus trans- $N$-deoxyribosylase. Chem. Res. Toxicol. 9:1140-1144.
Singer, B. and Grunnenberger, D. 1983. Molecular Biology of Mutagens and Carcinogens. Plenum, New York.

Srivasta, P.C., Robins, R.K., and Meyer, R.B. 1988. Synthesis and properties of purine nucleosides and nucleotides. In Chemistry of Nucleosides and Nucleotides (L.B. Townsend, ed.) pp. 113281. Plenum, New York.

Uerkvitz, W. 1971. Purification of nucleoside 2-deoxyribosyltransferase from Lactobacillus helveticus. Eur. J. Biochem. 23:387-395.

\section{Key Reference}

Uerkvitz, 1971. See above.

Decribes the purification and crystallization of the transferase.

Contributed by Nathalie C. Schnetz-Boutaud, Marie-Christine Chapeau, and

Lawrence J. Marnett

Vanderbilt University

Nashville, Tennessee 